\title{
Decoding Cli-Fi Dynamics in Barbara Kingsolver's Flight Behaviour
}

\author{
Ashna Francis \\ Guest Lecturer in English \\ College of Applied Science \\ Kundara, Kerala, India \\ ashnafrancis1417@gmail.com
}

\begin{abstract}
Flight Behaviouris an integration of many important issues that humanity faces today like climate change, global warming, species extinction, and the advent of the age of Anthropocene. The novel is set in rural Tennessee and it explores the reaction of a bible belt community to the arrival of millions of monarch butterflies on the mountains of their hometown. This astonishing phenomenon is branded as a miracle by the townsfolk but the arrival of a research team reveals the troubling truth behind the butterflies' presence. They have been driven away from their usual Mexican winter grounds because of devastating mudslides and flooding that affected the area. Kingsolver, in simple words, expresses the alarming reality of how changing climate affects biodiversity and leads many species to the verge of extinction. She artfully links the monarch's struggle for survival with the protagonist's search for identity, independence and self-expression.

Keywords: Barbara Kingsolver, Anthropocene, Climate Fiction, Biodiversity, Species Extinction.
\end{abstract}

Anthropogenic climate change is one of the defining challenges of the twenty first century. We are headed towards a future that is hard to contemplate. At present, global emissions are reaching record levels, the past four years being the hottest on record, coral 
reefs are dying and sea levels are rising. Such drastic changes in earth's natural ecosystems point towards the advent of Anthropocene. Since the Industrial Revolution, humans have altered the Earth's atmosphere, resulting in extreme weather changes and unpredictable climate. This period of observable human impact on the Earth's ecosystems has been called the Anthropocene. "Humanity has so far played the role of planetary killer, concerned only with its own short-term survival ... The Anthropocene, one might say, has been an unintended consequence of human choices"(Chakrabarty 210).

The Anthropogenic climate change that has impacted the Earth has also affected our literature. So, it is no surprise that a literary phenomenon has grown over the past decade which seeks to help us imagine the impacts of climate change in clear language. Climate fiction, popularly abbreviated as Cli-fi, is a branch of literature that deals with the effects of climate change on human society. The word Cli-fi is credited to Dan Bloom, an English teacher and former journalist, who coined it in 2007. Bloom felt that climate change was a subject that did not receive the attention due it's importance and sought ways to promote stories that bought it to the forefront.

Cli-fi novels mostly takes place in the near future and presents before us a planet that is ravaged by extreme climatic cataclysms. Climate fiction brings real science to the readers in a manner that is easily comprehensible. It can succeed in making common man understand the stark realities associated with climate change, which is otherwise considered an abstract concept. Climate fiction incorporates a host of works produced from authors such as Margaret Atwood, Paolo Bacigalupi, Kim Stanley Robinson, Mindy McGinnis, Barbara Kingsolver, J.G. Ballard, Saci Lloyd, Omar El Akkad, Maja Lunde, Nnedi Okorafor and Ian McEwan. These authors have contributed greatly to the growth of Cli-fi as one of the most relevant genres of literature in this era. 
Among these writers a name that deserves distinct acknowledgement is that of Barbara Kingsolver, an American writer, and political activist whose best-known novels talk about the endurance of people living in inhospitable environments and the beauty to be found even in such harsh circumstances. Her works often encompasses themes like social justice, biodiversity, climate change and the interaction between humans and their communities. She is known for her ingeniously crafted literary works like, The Bean Trees (1988), Animal Dreams(1990), Pigs in Heaven(1993), The Poisonwood Bible(1998), Prodigal Summer (2000), The Lacuna (2009), Flight Behaviour (2012) and Unsheltered (2018).

Flight Behaviour is a very touching novel whose message about climate change is both timely and true and cannot be ignored. The novel is set in rural Tennessee and is centered around Dellarobia, a 28-year-old housewife, who had to give up her education when she became pregnant at seventeen and got married to Cub Turnbow. One day she happens upon millions of monarch butterflies glowing like a 'lake of fire' in the mountains behind her home. This is immediately branded as a miracle by the townsfolk of Feathertown who are extremely religious. But the arrival of a research team led by an entomologist, Ovid Byron, reveals the troubling truth behind the butterflies' presence. They've been driven away from their usual Mexican winter grounds because of devastating mudslides and flooding that affected the area.

By foregrounding the plight of the monarchs Kingsolver also addresses the problem of how climate change affects biodiversity. Many factors threaten biodiversity, not just the activities that kill species directly, such as hunting, fishing, or pesticide use, but also the temperature and moisture changes associated with climate change. It may lead to habitat change and, eventually, habitat loss, which has a severe impact on biodiversity. In Flight Behaviour, the monarch butterflies are depicted as a beautiful species which has lost its familiar habitat and is now facing the threat of extinction because of changing climes. 
As soon as the news of the monarch's arrival spreads, the Turnbows get many visitors who wants to see them. One of these visitors turns out to be a Mexican family, Lupe and Renaldo and their daughter Josefina. Josefina explains that Reynaldo was a guide who used to take people to see these monarchs in their hometown in Mexico where they had always overwintered before. But last year a landslide occurred and the entire monarch population lost its natural habitat. Josefina lost her home and her entire family had to move to Tennessee and work for menial wages. Dellarobia couldn't even conjure up words of sympathy as she had absolutely no idea what to say to a family that had lost their entire world.

Burley Turnbow, Dellarobia's father-in-law, is a man who controls almost every aspect of his son's life. He fixes a contract with some loggers in order to clear cut the forest behind Dellarobia's home all the way to the top of the mountain. Dellarobia is disturbed by this news as she had done some research about the town in Mexico, where Josefina and her family lost their home and logging was a part of it. "They had clear-cut the mountainside above the town, and that was said to have caused the mudslide and floods when a hard rain came" (Kingsolver 189). Dellarobia's suggestion that they don't log the mountain is met with mocking disdain from Cub who is wary of people who wants to save trees for the tree's sake. Dellarobia was not aware of climate change patterns, but she did understand that the threat Josefina's family faced could very well be her own reality if this logging took place.

Already restless in her marriage to the passive Cub, Dellarobia takes a mammoth leap when she starts working with the research team led by Dr Byron. She accompanies the research team up the mountain and realises with growing regret that the heavy rain is affecting the monarch population quite adversely. She imbibes new knowledge about the natural world around her and recognises for the first time that she is part of an interconnected system. She sees the struggle of the monarchs to survive against extremely challenging weather patterns and is inspired to struggle for her own growth and independence. She 
decides to break out of her marriage, which she finds suffocating and realises for the first time that her decision to marry Cub itself was based on the wrong reasons. She also vehemently opposes the decision to clear cut the forests and conceives the courage to stand up against her in-laws and make a difference. Kingsolver draws upon her knowledge of the natural world to create comparisons between the monarchs and the humans around them at every turn. They mirror each other's struggle for growth and survival.

Flight behaviour ends with the depiction of a world unravelling into fire and flood. "The radio had churned all morning with strange accounts, regardless of station. Flood and weather warning, disasters" (Kingsolver 591). Dellarobia was alone at home, with Cub and Cordelia, her daughter,outside and Preston, her son, at school. The flood came out of nowhere with the water rising dangerously within a short time. Dellarobia was at first worried about her children, who were facing this by other means, but she soon becomes resigned to the fact that they would have to survive this just like herself. Evenadmist the flood,the astonishing number of monarchs dotted on every visible surface captures Dellarobia's attention. Kingsolver shows nature rising up against all odds through the picture of the resurrecting monarchs. "They would gather on other fields and risk other odds, probably no better or worse than hers" (Kingsolver 597). Their sight once again lends her the strength to fight and to survive. As the monarchs take flight at the end of the novel she is also freed from her trapped domestic life.

Throughout the novel, Kingsolver engages the readers in discussions of environmental issues in the form of simple and subtle conversations between the characters. She doesn't sugar-coat the alarming facts of climate change and presents it in the form of earnest conversations between Dr Byron and Dellarobia. They discuss topics like greenhouse gasses, world's average temperature and the thermal stability of the planet in a way that 
makes it easily understandable to the common reader. Readers understand the depth and relevance of such topics when Dellarobia herself first learns it.

Dellarobia comes to realize that the major problem humanity face right now is the lack of people's responsibility to their natural surroundings. Her environmental consciousness helps her to find her real identity and to see the whole world in a new light. Flight Behaviour acts as a parable that prompts the readers to recognise the fact that by being passive observers to the atrocities committed against nature, we are silently consenting to our own doom, as man and nature are inevitably bound together. Kingsolver reveals how a closer and humble relationship with nature is important for humans to understand themselves and their relationship with others. 


\section{Works Cited}

Chakrabarty, Dipesh. "The Climate of History: Four Theses." CriticalInquiry, Vol. 35, No. 2, 2009, pp. 197-222. JSTOR, www.jstor.org/stable/10.1086/596640.

Kingsolver, Barbara. Flight Behaviour. CPI Group, 2013.

Maslin, Mark. Climate Change: A Very Short Introduction. 3rd ed., Oxford UP, 2014. 